\title{
New public management in Iran's health complex: a management framework for primary health care system
}

\author{
Jafar Sadegh Tabrizi ${ }^{1}$, Elaheh HaghGoshayie ${ }^{2}$, Leila Doshmangir ${ }^{3}$ and Mahmood Yousefi ${ }^{4}$ \\ ${ }^{1}$ Professor, Tabriz Health Services Management Research Center, Tabriz University of Medical Sciences, Tabriz, Iran \\ ${ }^{2}$ Ph.D. Candidate, Healthcare Management, Iranian Center of Excellence in Health Management (IceHM), School of \\ Management and Medical Informatics, Tabriz University of Medical Sciences, Tabriz, Iran \\ ${ }^{3}$ Assistant Professor, Health Policy, Department of Health Services Management, School of Management and Medical \\ Informatics, Tabriz, Iran \\ ${ }^{4}$ Assistant Professor, Health Economics, Department of Health Services Management, School of Management and \\ Medical Informatics, Tabriz, Iran
}

\begin{abstract}
Background: New public management (NPM) was developed as a management reform to improve the efficiency and effectiveness in public organizations, especially in health sector. Using the features of private sector management, the managers of health organizations may try to implement the elements of NPM with the hope to improve the performance of their systems. Aims: Our aim in the present study was to identify the elements and infrastructures suitable for implementing NPM in the Iranian health complex. Method: In this qualitative study with conventional content analysis approach, we tried to explore the NPM elements and infrastructures in Iranian public health sector. A series of semi-structured interviews $(n=48)$ were conducted in 2016 with a managers in public and private health complex. Three focus group discussions with nine faculty members were also conducted. A data collection form was used to collect the demographic characteristics and perspectives of the participants. Findings: From the perspective of managers, managerialism, decentralization, using market mechanism, performance management, customer orientation and performance budgeting were the main elements of NPM in the Iranian context. The most important infrastructures for implementing this reform were as follows: education and training, information technology, the proper use of human resources, decision support systems, top management commitment, organizational culture, flexibility of rules, rehabilitating of the aging infrastructures, and expanding the coverage of services. Conclusion: The NPM was generally identified to be an effective replacement for the traditional administration method. These reforms may be helpful in strengthening the public health complex and the management capacity, as well. NPM also seems to be useful in interacting the public health sector with the private sector in terms of personnel and resources, performance, reward structure, and methods of doing business.
\end{abstract}

Key words: health complex; health managers; new public management; public administration; primary health care

Received 18 July 2017; revised 6 November 2017; accepted 13 November 2017;

first published online 9 January 2018

Correspondence to: Elaheh HaghGoshayie, Ph.D. Candidate in Health Services Management, Tabriz Health Services Management Research Center, Tabriz University of Medical Sciences, Tabriz, 5517746463, Iran. Email: ezd_ehm2010@yahoo.com

\section{Introduction}

In the last two decades, public management reforms, as international phenomena, have become serious subjects in the majority of

(c) Cambridge University Press 2018 
developed and developing countries (Batley, 2004; Burau and Fenton, 2009). It is essential to consider these reforms to respond to the economic, organizational and cultural changes and to evaluate the level of improvement in a government effectiveness and, to critique the costly public sector (Dunleavy and Hood, 1994; Elias Sarker, 2006).

As a part of these reforms, a paradigm of public sector management has been known as new public management (NPM) (Hoyle, 2011). The NPM was begun in the late 1980s in developed countries such as the United Kingdom and Australia and was improved after implementation in various countries over the years (Pollitt, 1990; Burau and Fenton, 2009; Pollitt and Bouckaert, 2011; Keisu et al., 2016; Willis et al., 2016) This reform was created as an answer to the differences found in the performance of public sector compared with the private sector, and due to the poor incentive structures that may led to weak performance in public sector (Pallott, 1999; Shaw, 2004).Therefore, policy makers and reformers want to apply such reforms to ensure that the public sector organizations become look like their private sector counterparts (Poole et al., 2006; Brinkerhoff and Brinkerhoff, 2015).

In addition, these reforms are described as normative conceptualizations of public administration which include several inter-related components such as decentralization, paying attention to the human resources, utilization of pay-for-performance, increasing autonomy of public managers, use of market mechanism, emphasizing on output control, disaggregation, increasing competition and innovation and emphasizing great discipline and well economical use of resources (Dunleavy and Hood, 1994; Hood, 1995; Austin, 2004; Sarker, 2005).

Although in many countries, the private health sector has more than $50 \%$ of the total resources related to the health sector (Kalimullah et al., 2012), it is reported to be faced with a market failure in the provision of health services (Buse and Walt, 2000; Mills et al., 2002). On the other hand, health sector, like public sector is faced with failure to provide health services for people. Therefore, it is necessary for health sectors to participate in both public and private sectors (Buse and Walt, 2000; Soeters and Griffiths, 2003). To do so, policy makers and managers in the health sector, like those in the other sectors, try to use positives characteristics of NPM (Shaw, 2004).
In a majority of countries, NPM policies have been applied in health sector to attain different goals including decreasing health care expenditures, increasing efficiency and effectiveness, cost saving and improving the quality of public services (Simonet, 2008; Connell et al., 2009; Acerete et al., 2011). For example in the United Kingdom, provider/funder dichotomy was developed as a radical market-based mechanism (Simonet, 2008). In New Zealand, Singapore and some other countries, it is emphasized on the rule of law, market-based approaches and contract-like arrangements (Aucoin and Peter, 1995; Elias Sarker, 2006). Denmark and Norway also tried to improve the management practices and to privatize the publicly owned enterprises (Jensen, 1998; Guthrie et al., 1999).

Since 1979, in Iran, like other countries, the health policy makers ratified and performed various laws to achieve 'Health for All' (Keisu et al., 2016). One of the most important transformations during this period was the merging of medical education in Ministry of Health and the formation of the 'Ministry of Health and Medical Education (MOHME)' at the national level (Willis et al., 2016). Another reform was the establishment of 'medical sciences universities' at the provincial level (Mehrdad, 2009).

At the district level, 'town' was accepted as an administrative standard for the development of health care units. In this level, a district's health network includes the district health center (urban and rural health centers, health posts and health houses) and the district general hospital (AsadiLari et al., 2004). In 2005, family physician program and universal health insurance were implemented in all Iranian rural areas and after seven years, in 2012, these programs were performed in some urban areas (Nasrollahpour Shirvani et al., 2010), as well. However, similar to other countries, there are many problems in the public health sector of Iran (Mehrdad, 2009).

Despite these transformations, the organizational structure in this section remained unchanged in the recent three decades (Zanganeh Baygi et al., 2016). The traditional primary health care system (PHC) in this sector have had some remaining problems including low accessibility in urban areas, low availability of expert human resources, lack of effective performance measurement, and insufficient quality of health care 
(Farahbakhsh et al., 2012; Kiaei et al., 2015). The World Bank also, in a report on the Iranian health system in 2007, highlighted many achievements of the system after extension of the health care networks, and clarified some existing problems including the problems of structure, strong focus on decision making, variety of service delivery systems and the fragmentation of this system, especially in the cities (Gressani et al., 2007). It was stipulated in this report that the current organizational PHC structure in Iran was significantly inefficient (Takian et al., 2010). Moghadam et al. (2012) have announced many weak points for the Iranian health system in urban areas. In addition, multiple centers with different service providers have caused problems in rendering the services (Seyedin and Jamali, 2011).

Therefore, health system reforms in providing PHC services have been considered as one of the important priorities of the current government (Party of Development and Moderation) (Hafezi et al., 2009). In order to achieve universal health coverage and equity in health care, the public and private health complex was created in 2013 to provide health services in urban areas, especially the slum and underprivileged urban areas (Tabrizi et al., 2016).The aim of establishing the health complexes was to implement an effective management system and organizational structure for development in the current situation (Tabrizi et al., 2016).

Health complex is a new PHC reform model in Iran which was developed as a part of Health Sector Evolution Plan (Tabrizi et al., 2016). This system provides actively comprehensive and integrated health services within the policy framework of the Ministry of Health in a defined geographic area (Jabari et al., 2007). Health complex was designed based on the capabilities of public and private sectors for an entire population in a region and based on the defined per capita and was supervised by the town's health care and treatment network. Each health complex covers a population about 40000-120000 people and a health complex includes a management center, several health centers and one comprehensive health center (Tabrizi et al., 2016).

Private health complexes are managed by a manager with the tasks of planning, coordinating, monitoring and evaluating staff units, providing resources, responding and so on. The managers are under supervision of the director of the complex, but managers in the public health sector still do not have freedom and cannot manage like their counterparts in the private sectors (Farahbakhsh et al., 2012).

Based on what mentioned above, The Iranian health planners and policy makers are trying to benefit the principles of NPM (beneficial characteristics of the private sector, market-type mechanisms, utilization of the new payment methods and decentralization), which may be assistive in increasing the efficiency and effectiveness of public health complexes and in improving the management structures of public health complexes. The Iranian health planners and policy makers want public health complexes to be managed like private health complexes and want each public health complex to be directed as independently and empowered as possible. As an effort to help health managers and policy makers in finding a better understanding on NPM in the Iranian Health System, this study aimed to identify the main elements and infrastructures of implementing NPM in East Azerbaijan Province public health complex, Iran.

\section{Methods}

\section{Study design and sampling}

This qualitative study with conventional content analysis approach was carried out between October 2016 and March 2017 in East Azerbaijan in Iran. The characteristics of the health complex in East Azerbaijan province is described in Table 1. We conducted a series of semi-structured in-depth interviews with a purposive sample of participants $(n=48)$. Also, we conducted three focus group

Table 1 Characteristics of health complex in East Azerbaijan province

\begin{tabular}{|c|c|c|c|c|}
\hline \multirow[b]{3}{*}{$\begin{array}{l}\text { Type of health } \\
\text { complex }\end{array}$} & \multicolumn{4}{|c|}{ Health complex } \\
\hline & \multicolumn{2}{|c|}{$\begin{array}{l}\text { Management } \\
\text { center }\end{array}$} & \multicolumn{2}{|c|}{ Health center } \\
\hline & Frequency & $\%$ & Frequency & $\%$ \\
\hline Public & 19 & 52.80 & 84 & 57.93 \\
\hline Private & 17 & 47.20 & 61 & 42.07 \\
\hline Total & 36 & 100 & 145 & 100 \\
\hline
\end{tabular}


Table 2 Profile of interviewees

\begin{tabular}{|c|c|c|c|c|}
\hline \multicolumn{3}{|l|}{ Participants ( $n=48)$} & Frequency & $\%$ \\
\hline \multicolumn{5}{|l|}{ Gender } \\
\hline Male & & & 38 & 79.17 \\
\hline Female & & & 10 & 20.83 \\
\hline \multicolumn{5}{|c|}{ Highest level of educational degree } \\
\hline Bachelors (BA) & & & 5 & 10.41 \\
\hline Masters (MS) & & & 8 & 16.67 \\
\hline Ph.D. & & & 2 & 4.16 \\
\hline MD & & & 32 & 66.67 \\
\hline MD, Ph.D. & & & 1 & 2.09 \\
\hline & Minimum & Maximum & Mean & SD \\
\hline Average age (years) & 28 & 55 & 47.55 & 8.37 \\
\hline $\begin{array}{l}\text { Average work } \\
\text { experience (years) }\end{array}$ & 1 & 32 & 17.12 & 8.48 \\
\hline
\end{tabular}

Table 3 Profile of the participants in the focus group discussions

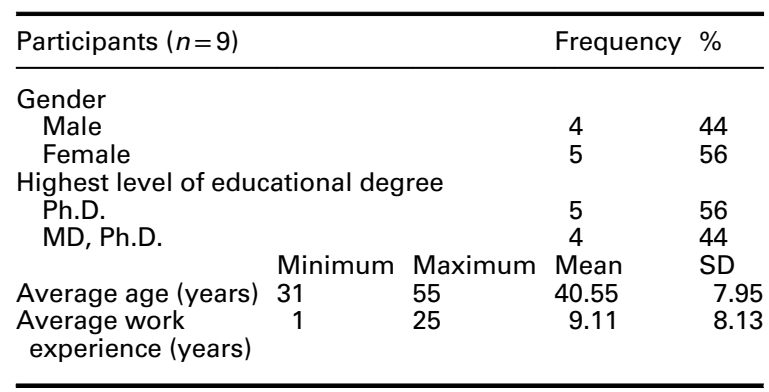

discussions (FGDs) with nine participants. Participants in the in-depth interviews were the managers of health centers in both public and private sectors of East Azerbaijan health complex. The main descriptive characteristics of these participants are summarized in Table 2. Also, the participants in FGDs consisted academy members of health services managers, health policy makers, health economists and physicians with experience in heath complex management (Table 3). A formal letter was sent to the health complex and emails of faculty members from the school of management and medical informatics which was included the objective of our study, a description on the characteristic of NPM and its elements as well as a consent form to participate in the interviews and FGDs.

\section{Data collection}

To collect data, three FGD sessions were held with faculty members, and 48 in-depth interviews were established with the managers in public and private health complex. Data were gathered through verbatim transcripts of semi-structured recorded interviews. Before interviews, we contacted several top and middle managers of each center to identify the name and to define a set of reform initiatives, which were currently progressed. Each interview and/or FGD lasted between 60 and $90 \mathrm{~min}$. The interviews were continued until data saturation. The interviews and FGDs were conducted by one researcher and one note-taker. Our research questions (RQ) included the following items:

$\mathrm{RQ}_{1}$ : What are the managers' perspectives toward NPM?

$\mathrm{RQ}_{2}$ : Which elements of NPM are suitable for public health complex?

$\mathrm{RQ}_{3}$ : What infrastructures are needed to implement NPM in the Iranian public health complex?

\section{Analytical approach}

The structure of this qualitative analysis was based on a prior knowledge about NPM to investigate the elements and infrastructures for better implementation of NPM. So, the research team applied a deductive content analysis process using the theoretical framework of previous studies. The texts were read again and again and then were encoded and categorized in accordance with the created themes for analysis. Conventional content analysis approach was applied, and the themes were rechecked with the participants. To ensure the reliability of our analysis, all the analyses were separately reviewed by two researchers in the study team, and in the case of disagreement, the team made the final decision on the theme.

\section{Findings}

The 48 interviews were performed from October 2016 to March 2017. The participants included the managers with 1-31 years of experience in health care fields. The interviewees included 10 women and 38 men. The majority of participants were physicians $(n=32)$. FGDs were conducted with nine faculty members. The participants had 1-25 years of work experience. Four out of nine participants in the FGDs (56\%) were Ph.D. in health services management, health policy and health economics.

Almost all of the participants had a positive attitude toward implementing NPM. They 


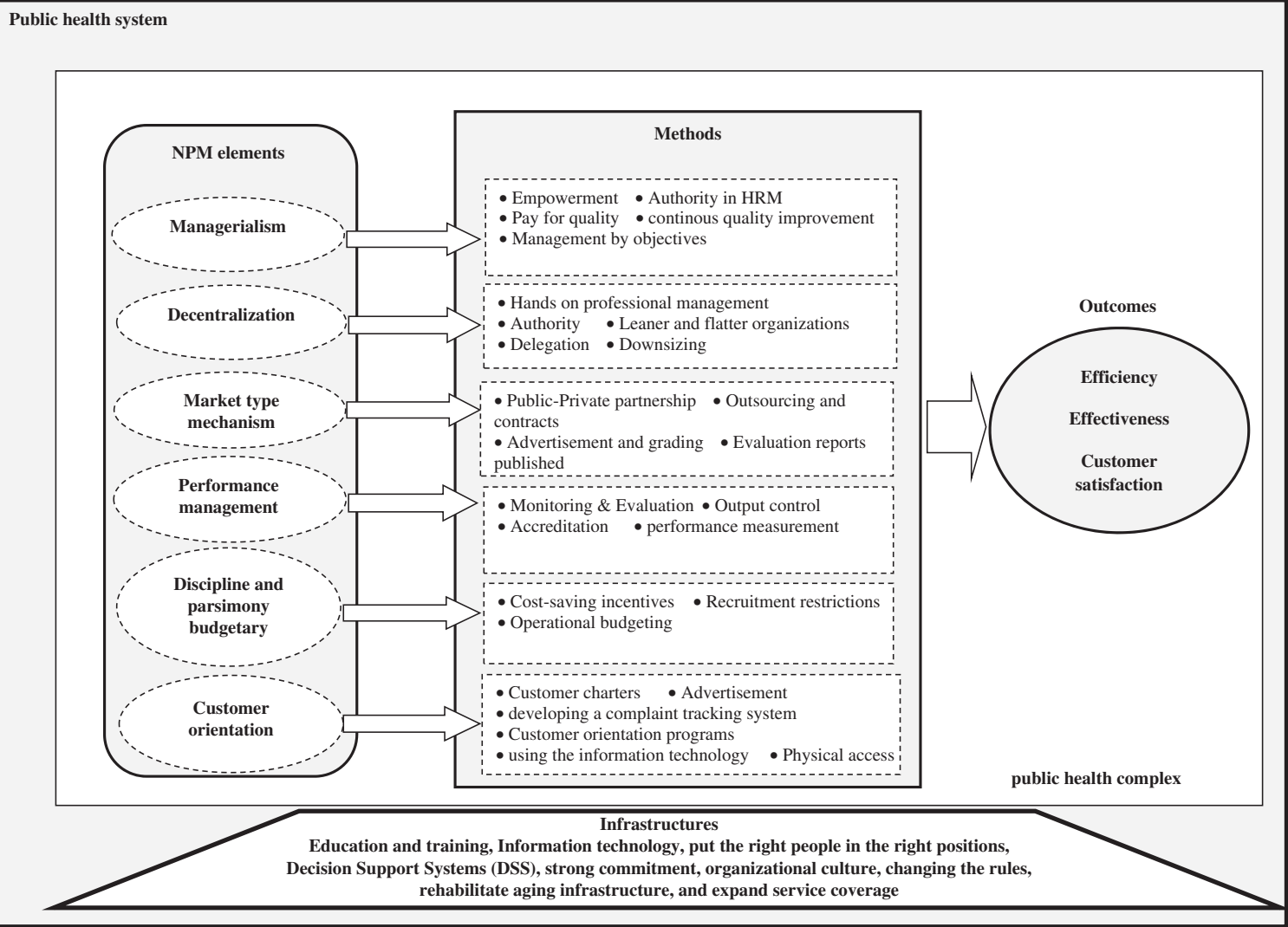

Figure 1 Framework of new public management (NPM)

believed that if NPM were correctly implemented, the level of efficiency in public health complex may be increased. According to two of the participants:

'Yes, the NPM has been considered as a good goal for organizations but when we can develop this reform in our public healthcare system that our organizations would have appropriate infrastructures.'

(Ph.D.)

'Yes, managers don't have authority in health complex and NPM tries to increase the power of manager. Therefore, in my idea, it is a good reform for this sector and it leads to efficiency and effectiveness.'

After data analysis, we designed a framework for NPM to better understand the interactions between the elements in the public health complex (Figure 1).

Primary Health Care Research \& Development 2018; 19: 264-276
According to the final codes extracted from the texts, the suitable elements of NPM for public health complex were categorized into six domains: managerialism, decentralization, market-type mechanism, performance measurement and new model of control, discipline and parsimony budgetary process and customer orientation.

\section{Managerialism}

One of the elements of NPM was managerialism. From the perspective of managers, this element can help managers in public health organizations to manage like their counterparts in the private sector. According to three of the participants:

'When I have authority about human resource management, like managers in the private sector, I can fairly use the rewards and punishment about my staff.' 
'In my system, the payments aren't based on performance. There aren't difference between good and bad staff; therefore, good staff don't have motivation for working while in the private sectors the payments are based on pay-for-performance.'

'My staff don't have information about their job description, because it has written ambiguous.'

(MD)

The sub-themes for this element were categorized into: empowerment, authority in health resource management, pay for quality, continuous quality improvement and management by objective.

\section{Decentralization}

Authority, leaner and flatter organizations, hands-on professional management, downsizing and delegation were identified as decentralization and one of the elements of NPM which is useful for managing public health complex. Two participants stated that:

'We should allow the managers to manage. In the public sector, unlike the private sector, managers can't make decisions independently and the main decisions are made using the bureaucratic system.'

$$
\text { (MD, Ph.D.) }
$$

'In public health complex, the managers in all functions are dependent on their senior managers, and bureaucracy is very common. In my opinion, we can't eliminate bureaucracy in the public sector, but the system should give the delegation to managers and allow them to have a prominent role.'

(MD)

Private and public managers believed that decentralization was an important element in NPM and the implementation of the other elements are related to this element.

\section{Market-type mechanism (MTM)}

According to one participant, "if we want to create competitive environment, we must use the semimarket. Furthermore, our organizations can utilize the benefits of private sector using contracting and outsourcing. For example, we can contract with private sector about pharmacy management.'

We identified four sub-themes for this element of NPM: public-private partnership, outsourcing and contracts, advertisement and grading and publishing evaluation reports. From the perspective of managers, MTM may help public sector to less monopolized the market in proportion to those that was before.

Performance management and new models of control

Another element of NPM was performance management. Monitoring and evaluation, output control, accreditation, performance measurement were the main sub-themes of performance management. Three managers stated that:

'We need performance measurement because in our organization, monitoring is happened once a season and the payments are not based on performance and, moreover, there are not monitoring agencies in the public sector.'

(MD)

'There are insurance deductions (30\%) in public health complex, while in private sectors we don't have any deduction, because we carefully check all of the medical documents but in public health system this is not being done. Public sector monitoring is based on input control, and it leads to inefficiency. Thus, we need a new model of control that will be based on output control.'

(MD)

'In our system, the majority of audits are conducted at the organizational level and good staff are not motivated for this. NPM can help us using performance management with which we can recognize good staff from bad staff.'

Discipline and parsimony budgetary process

One participant added that, 'In the public organizations, the traditional budgeting has been used and the waste of resources is very high. Moreover, the most of staff are formal recruitments and don't 
have motivation to work, because they do not afraid of getting fired. We have to try to use downsizing strategies to resolve this problem. In my opinion, NPM can help us in knowing the real amount of resources needed in our organizations. So, we have to use operational budgeting. It leads to increase efficiency, motivation and performance among staff.'

(Ph.D.)

Cost-saving incentives, recruitment restrictions and operational budgeting were the sub-themes of this element of NPM.

\section{Customer orientation}

Attention to the customer was one of the main elements of NPM. Public managers noted that customer orientation is a missing ring (Persian te) in Iranian public organizations and NPM without attention to the customer is incomplete. We identified six sub-themes for this element of NPM: customer charters, advertisement, developing a complaint tracking system, customer orientation programs, using the information technology and physical access.

'The expectations of customers are different from one geographic area to another. So, our planning should be based on customer needs. In public health complex, and through advertisement, we can inform people about our organization's activities.'

(MD)

'People tend to the private sector more than the public sector, because they think that the private sector pay more attention to a customer. Therefore, we have to create a customer-oriented culture in the public organizations, and attempt to involve people in planning for their health. In addition, we can use information technology for communication with customer. For example, we can use SMS system for conveying information to the customers.'

From the perspective of managers participated in the present study, nine main infrastructures are necessary to implement NPM (Figure 2). NPM may not be correctly performed in the absence of trust between managers and staffs. Furthermore, providing quality services is depended on the employees and managers attitude, skills, commitments and efforts. Moreover, the public sector managers should use information technology to assemble a mixture of technical skills with financial resources needed to implement the reforms. Flexibility and changing in rules may provide a basis for motivating, expanding, and managing the government's human resources.

\section{Discussion}

In this qualitative study, we identified six elements of NPM which are suitable for public health complex from the perspectives Iranian health managers. According to the results, the managers had an overall positive attitude toward NPM. Kalimullah et al. (2012) identified five elements of NPM announced in the most of other similar studies: downsizing, managerialism, decentralization, debureaucratization and privatization. In another study six elements were reported for NPM: decentralization, privatization, orientation of the results from the market mechanism toward the public sector, private sector management practices, and introduction of participation. In this study, the elements of NPM were reported to be successfully implemented in public organizations (Babravicius and Dzemyda, 2012).

From the perspective of participants in the present study, if the elements of NPM are selected properly and in the case of infrastructures provided, the resulted reforms would improve the performance of the public health sector. Therefore, before implementing NPM, public health complex should provide the essential infrastructures. Studies have noted that developing countries cannot provide resources and managerial capacity for adopting NPM reforms (Flynn, 2000). In these countries, weak administrative and implementation capacity and resource constraints have been reported as the main barriers to public administration and management reforms (Batley and Larbi, 2004; Fernandez and Rainey, 2006). Therefore, before implementation of NPM, managers and employees need to be completely informed about such reforms. Primarily, organizational culture should be revised and information technology should be developed. Also, The organizations should be rehabilitated from the aging 


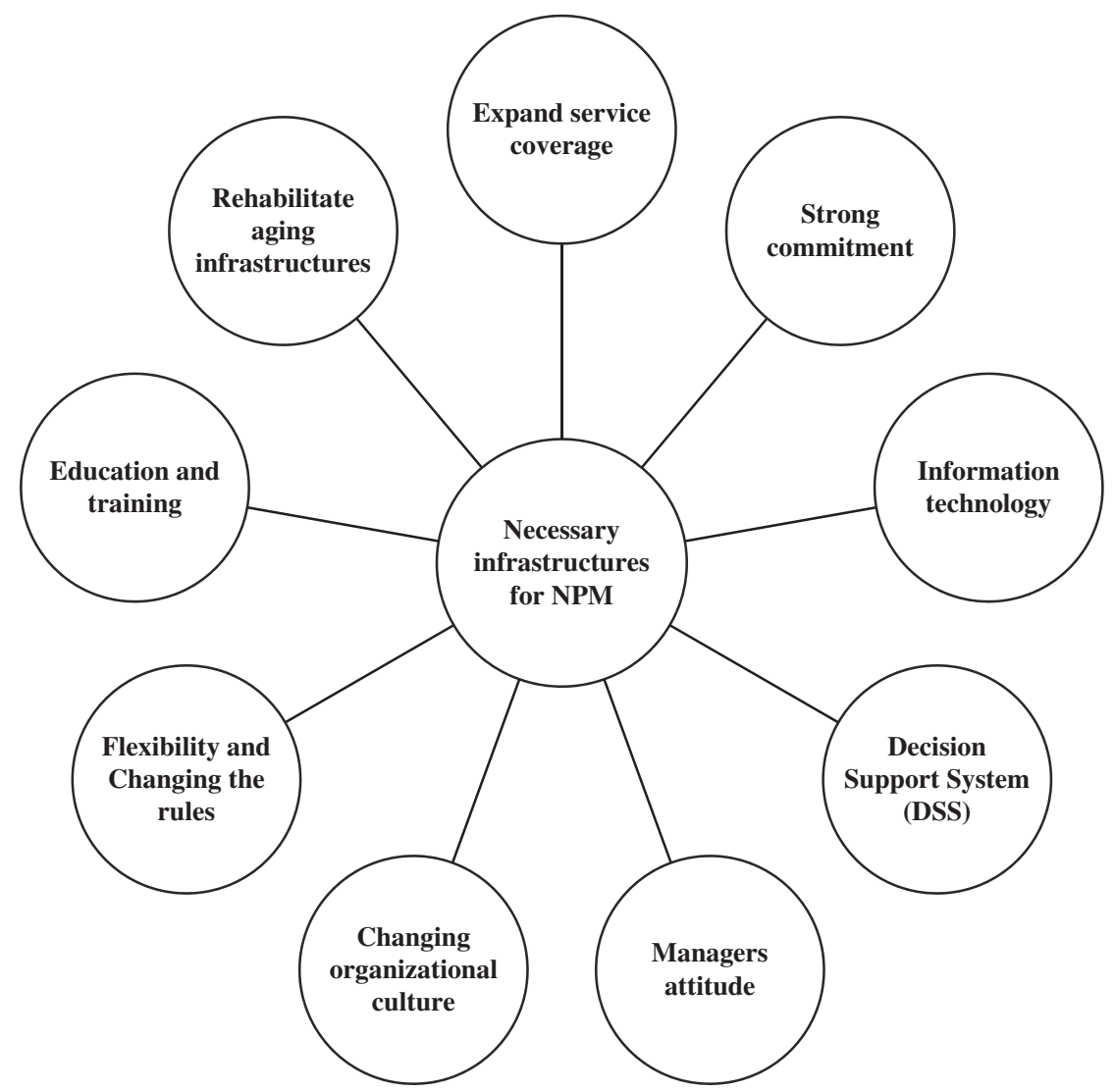

Figure 2 Infrastructures for implementing of new public management (NPM) in public health complex

infrastructures and strong commitment between managers with suitable tools should be created. In many developed countries (England, Canada and Australia) and some developing countries (Egypt, Malaysia and New Zealand), the governments after providing appropriate infrastructures have been successfully performed the NPM reforms (Aucoin and Peter, 1995; Hood, 1995; Barzelay, 2001; De Boer et al., 2007; Constantinou-Miltiadou, 2015).

The most of previous studies mentioned decentralization, market-type mechanism, performance measurement, privatization, private-sector style management practices and attention to customer as the main elements of NPM (Promberger and Rauskala, 2003; Hammerschmid and Van de Walle, 2011; Engida and Bardill, 2013; Bačlija, 2014; Constantinou-Miltiadou, 2015), which was similar to those found in the present study.
In NPM, aims are to apply new management methods in public organizations, with the hope to be resulted in a context with an appropriate environment for empowering the employees (Kaymakçı and Babacan, 2013). Public managers in our study were interested in learning new methods of management. They believed that service quality and performance in public health complex may be improved through applying managerial skills. According to their opinion, employees need to be empowered, as well.

As noted by Diefenbach (2009) 'the proponents of NPM believe that it will improve public services by making public sector organizations much more business-like' (Diefenbach, 2009). Our study showed that the managers in public health complex tend to have freedom in management, and they want to participate in decision-making processes on human resource management and

Primary Health Care Research \& Development 2018; 19: 264-276 
budgeting. They mentioned the need for delegation of authority in their systems which may lead to motivation in management. They also announced the need for more participants on the compilation of strategic plannings.

In recent years, due to technology development and more attention to employee development, organizations are demanding more creativity and responsibility from their employees (Kaymakçı and Babacan, 2013). Organizations and employees prefer to have employees with creativity and accountability instead of senior management, which conducted employees' behavior and decisions (Quinn and Spreitzer, 1997). The managers in our study mentioned the need for using technology for benchmarking and relationship with customers. They also noted that if we want to have increased level of satisfaction among customers, improved management structures and time management, we should provide our customers with information technologies like SMS system and effective automation, as well.

Decentralization was another main element of NPM (Constantinou-Miltiadou, 2015) and one of the central factors in changing public sector and making new public administrations (Hope, 2001). Decentralization is a broad term, that may be defined as the transfer of authority or responsibility for decision making, planning, management or resource allocation from the central government to the field units, district administrative units, local government, regional or functional authorities, semiautonomous public authorities, parasitical organizations, private entities and nongovernmental private voluntary organizations (Dzimbiri, 2008). Decentralization also involves the delegation of more authority over the officials working within the field, and closer to the problems (Engida and Bardill, 2013). Moreover, downsizing may lead to decrease in the cost of public organizations (Ferlie, 1996). The results of our study showed that decentralization is somewhat implemented in the Iranian health complex but the rules are still very inflexible and bureaucracy is high. They mentioned that if we want to work with efficiency, senior managers should be trusted by public health managers and the bureaucracy should be decreased, as well.

Managers in our study noted their tendency to manage like the managers in the private sectors. They said that authority, as a factor of decentralization is an essential element of NPM needed for the well management of health systems. From their point of views, authority and effective performance are correlated together. As a result, if organizations want to maintain their managers with accountability for the output, they should give the managers some levels of control over their subordinates.

In Denmark, the delegation of financial authority and global budgets have been introduced as NPM reforms (Green-Pedersen, 2002). In Sweden, individual agencies are responsible for authority on employment and human resource management. Furthermore, collective bargaining among locallevel public employers, has widely been decentralized and wage-setting systems have been reformed to make them more flexible, individualized and performance-oriented (Bach and Bordogna, 2011). In the Cypriot public health sector, decentralization of managerial authority and creating flexibility to managers are main elements for NPM reforms (Constantinou-Miltiadou, 2015).

One of the elements of NPM mentioned by managers was performance management. The aim of this element is to report the outputs of public organizations and to apply these data to reward or penalize (Constantinou-Miltiadou, 2015). It is strongly and implicitly depended upon the other elements of the reform (Demediuk, 2009). Performance management in Cyprus was created in response to change environmental conditions, institutional resources and individual values. This element in this country may lead to new progress in the public sector through confirmation of vision, goals, strategies, performance measures and indicators and reporting systems. Many countries like United Kingdom, Australia, New Zealand and Norway have used performance management to improve the quality of services delivered to their citizens (Dixon et al., 1998; Hammerschmid and Van de Walle, 2011). Managers in our study explained that controls in the public health complex are based on inputs and not outputs which is insufficient for performance management. From their points of view, output and outcome controls as well as paying attention to quality and performance measurement are essential tools for public health complex. One of the main results of performance management was the need of public health complex to accreditation with the hope to encourage public and private health complex to 
compete for better and higher quality. In addition, accreditation may increase motivation between organizations for implementing effective activities.

The market-type mechanism, discipline and parsimony budgetary process and customer orientation were the other NPM elements emphasized by the health managers. Public health organizations, through market mechanisms (eg, competition with private sector, advertisement and grading), are supposedly forced to improve the quality of their services. Also, to improve the citizens' trust and confidence, public health organization should try to make their services friendly, convenient and comprehensive.

Discipline and parsimony budgetary process was another element of NPM that draws a relationship between what organizations did and the cost of what they did (McLaughlin et al., 2002). Many countries, after implementation of NPM elements, have found increased levels of efficiency and effectiveness in public organizations. For instance, some of the NPM elements were applied in Ghana's health sector included downsizing, management decentralization, contracting-out, and performance contracts. In New Zealand, privatization was used to transfer the ownership of public enterprises to the private interests. Furthermore, in the public sector, it was attempted to contract arrangements for service delivery. In order to enhance accountability among managers they also used agreements, plans, budgets, financial reports and presentation of budgets, estimates, plans, and annual reports. There is no budgeting in the Iranian public health complex and it depends on the higher levels. Managers in the present study explained their need to operational and flexible budgeting. Finally, customer orientation from the perspective of the managers was very important and they need to have resources for increasing efficiency. They also noted that to increase customer satisfaction, there is a need to correct implementation of all the elements of NPM.

\section{Strengths and limitations}

We were able to interview a large sample of participants. However, due to the nature of qualitative studies, we cannot generalize our findings to the other populations. Participants in our study included both men and women from various age groups. A large number of the managers contacted by us to participate in the study announced agreement to take part in the interview sessions which indicate an excellent response rate. Also, illustrative verbatim quotes were provided for each sub-theme to demonstrate the relationship between the interpretation and the evidence for increasing trustworthiness. We did not invite the health care managers of health centers in Tehran, Shiraz and Esfahan provinces due to the recent initiation of health complex in these provinces.

\section{Conclusion}

The health care sector is of particular concern to society due to its growing costs and operational complexities. In order to solve such problems, the NPM methods have been proposed in the health care systems of a majority of Organization for Economic Co-operation and Development countries with the hope to avoid discrimination and injustice and to control costs. NPM is also used to provide a system with better efficiency and progress while dealing with distrust. One of the important strategies in the Iranian health system reforms is health complex. In public health complex, the managers are requested to use the characteristics of private sectors in health care delivery. Based on the opinion of participants in our study, NPM reforms may be useful for the public sector and at first, the necessary infrastructures should be provided. This framework may be a good evidence for health policy makers in PHC systems. It may be a practical guide for implementing the management reforms in PHCs. These reforms may be helpful in strengthening the public health system and the management capacity, as well. NPM also seems to be useful in interacting the public health sector with the private sector in terms of personnel and resources, performance, reward structure, and methods of doing business.

\section{Acknowledgments}

This study was based on an evaluation approved by the Deputy of Research Affairs at Tabriz University of Medical Sciences. We are grateful to the East Azerbaijan Province Health Centre employees and health complex managers.

\section{Conflicts of Interests}

The authors declare no competing interest. 


\section{Ethical Standards}

Ethical code of project for this project is: TBZMED.REC.1395.461 that was approved by the ethical committee of Tabriz University of Medical Sciences (TUOMS). At the beginning of interview or FGD, verbal agreement was taken from the participants. The participants were told that if they want any time the voice-recording could be paused. Also, participants reassured that all information would remain confidential during the meetings.

\section{References}

Acerete, B., Stafford, A. and Stapleton, P. 2011: Spanish healthcare public private partnerships: The 'Alzira model'. Critical Perspectives on Accounting 22, 533-49.

Asadi-Lari, M., Sayyari, A., Akbari, M. and Gray, D. 2004: Public health improvement in Iran - lessons from the last 20 years. Public Health 118, 395-402.

Aucoin, P. and Peter, A. 1995: The new public management: Canada in comparative perspective: Montreal: Institute for Research on Public Policy.

Austin, C. 2004: The public and private interface in New Zealand primary health care. New Zealand Family Physician 31, 271-73.

Babravicius, J. and Dzemyda, I. 2012: Elements of new public management and implementation of" voucher in higher education" model in Lithuania Viesoji Politika ir Administravimas 11, 260-71.

Bach, S. and Bordogna, L. 2011: Varieties of new public management or alternative models? The reform of public service employment relations in industrialized democracies. The International Journal of Human Resource Management 22, 2281-294.

Bačlija, I. 2014: Local management and new public management. International Public Administration Review 9, 117-35.

Barzelay, M. 2001. The new public management: improving research and policy dialogue. Volume 3, United States of America: University of California Press.

Batley, R. 2004: The politics of service delivery reform. Development and Change 35, 31-56.

Batley, R. and Larbi, G. 2004. The changing role of government: the reform of public services in developing countries. Birmingham: Springer.

Brinkerhoff, D.W. and Brinkerhoff, J.M. 2015: Public sector management reform in developing countries: perspectives beyond NPM orthodoxy. Public Administration and Development 35, 222-37.

Burau, V. and Fenton, L. 2009: How healthcare states matter: comparing the introduction of clinical standards in Britain and Germany. Journal of Health Organization and Management 23, 289-303.

Primary Health Care Research \& Development 2018; 19: 264-276
Buse, K. and Walt, G. 2000: Global public-private partnerships: part II-what are the health issues for global governance? Bulletin of the World Health Organization 78, 699-709.

Connell, R., Fawcett, B., Meagher, G., Newman, S. and Lawler, J. 2009: Managing health care under new public management: a Sisyphean challenge for nursing. Journal of Sociology 45, 419-32.

Constantinou-Miltiadou, M. 2015: New public management in Cyprus: introduction, adoption and implementation of NPM, the relationship between the public and private sector. Leicester, UK: Centre for Labour Market Studies.

De Boer, H., Enders, J. and Schimank, U. 2007: On the way towards new public management? The governance of university systems in England, the Netherlands, Austria, and Germany. In Jansen, D., editor, New forms of governance in research organizations, (43-58): Dordrecht, the Netherlands: Springer, 137-52.

Demediuk, P. 2009: Conceptualising 'performance measurement' in the new public management. Australia: Victoria University, 1-34.

Diefenbach, T. 2009: New public management in public sector organizations: the dark sides of managerialistic 'enlightenment'. Public Administration 87, 892-909.

Dixon, J., Kouzmin, A. and Korac-Kakabadse, N. 1998: Managerialism-something old, something borrowed, little new: Economic prescription versus effective organizational change in public agencies. International Journal of Public Sector Management 11, 164-87.

Dunleavy, P. and Hood, C. 1994: From old public administration to new public management. Public Money and Management 14, 9-16.

Dzimbiri, L.B. 2008: Experiences in new public management in Africa: the case of performance management systems in Botswana. Africa Development 33, 43-58.

Elias Sarker, A. 2006: New public management in developing countries: an analysis of success and failure with particular reference to Singapore and Bangladesh. International Journal of Public Sector Management 19, 180-203.

Engida, T.G. and Bardill, J. 2013: Reforms of the public sector in the light of the new public management: a cases of Sub-Saharan Africa. Journal of Public Administration and Policy Research 5, 1.

Farahbakhsh, M., Sadeghi-Bazargani, H., Nikniaz, A., Tabrizi, J.S., Zakeri, A. and Azami, S. 2012: Iran's experience of health cooperatives as a public-private partnership model in primary health care: a comparative study in East Azerbaijan. Health Promotion Perspectives 2, 287.

Ferlie, E. 1996. The new public management in action. Oxford: Oxford University Press.

Fernandez, S. and Rainey, H.G. 2006: Managing successful organizational change in the public sector. Public Administration Review 66, 168-76.

Flynn, N. 2000: Managerialism and public services: some international trends. In Clarke, J. Gewirtz, S and Mclaughlin, E., editors, New Managerialism New Welfare? London: Sage, 27-44. 
Green-Pedersen, C. 2002: New public management reforms of the Danish and Swedish welfare states: the role of different social democratic responses. Governance 15, 271-294.

Gressani, D., Saba, J., Fetini, H., Rutkowski, M., Maeda, A. and Langenbrunner, J. 2007: Islamic Republic of Iran health sector review. volume I: main report. The World Bank Group. Human Development Sector, Middle East and North Africa 1, 1575-81.

Guthrie, J., Olson, O. and Humphrey, C. 1999: Debating developments in new public financial management: the limits of global theorising and some new ways forward. Financial Accountability and Management 15, 209-28.

Hafezi, Z., Asqari, R. and Momayezi, M. 2009: Monitoring performance of family physicians in Yazd. Toloo-e-behdasht $8,16-25$

Hammerschmid, G. and Van de Walle, S. 2011: The impact of the new public management: challenges for coordination and cohesion in European public sectors. Administrative Culture 12, 190-209.

Hood, C. 1995: The "New Public Management" in the 1980s: variations on a theme. Accounting, Organizations and Society 20, 93-109.

Hope, K.R. 2001: The new public management: context and practice in Africa. International Public Management Journal 4, 119-34.

Hoyle, L.P. 2011: New public management and nursing relationships in the NHS. Scotland, University of Stirling.

Jabari, B.H., Tabibi, S., Delgoshaei, B., Mahmoudi, M. and Bakhshian, F. 2007: A comparative study on decentralization mechanisms in provision of health services in health system of selected countries, and presenting a model for Iran. Journal of Health Administration 10, 33-40.

Jensen, L. 1998: Interpreting new public management: the case of Denmark. Australian Journal of Public Administration 57, 54-65.

Kalimullah, N.A., Alam, K.M.A. and Nour, M.A. 2012: New public management: emergence and principles. Bup Journal $1,1-22$.

Kaymakçı, K. and Babacan, S. 2013: Employee empowerment in new public management approach and a research. European Journal of Research on Education 2, 62-70.

Keisu, B.-I., Öhman, A. and Enberg, B. 2016: What is a good workplace? Tracing the logics of NPM among managers and professionals in Swedish elderly care. Nordic Journal of Working Life Studies 6, 27.

Kiaei, M.Z., Moradi, R., Hasanpoor, E., Mohammadi, M., Taheri, A. and Ahmadzadeh, M.S. 2015: Hospital managers' perception of recent health care reform in teaching hospitals of Qazvin, Iran. Biotechnology and Health Sciences 2, 24-9.

McLaughlin, K., Osborne, S.P. and Ferlie, E. 2002. New public management: current trends and future prospects. Routledge, London: Psychology Press.

Mehrdad, R. 2009: Health system in Iran. Japan Medical Association Journal 52, 69-73.
Mills, A., Brugha, R., Hanson, K. and McPake, B. 2002: What can be done about the private health sector in low-income countries? Bulletin of the World Health Organization 80, 325-30.

Moghadam, M.N., Sadeghi, V. and Parva, S. 2012: Weaknesses and challenges of primary healthcare system in Iran: a review. The International Journal of Health Planning and Management 27, 121-31.

Nasrollahpour Shirvani, D., Ashrafian Amiri, H., Motlagh, M., Kabir, M., Maleki, M.R., Shabestani Monfared, A. and Alizadeh, R. 2010: Evaluation of the function of referral system in family physician program in Northern provinces of Iran: 2008. Journal of Babol University of Medical Sciences $11,46-52$.

Pallott, J. 1999: Beyond NPM: developing strategic capacity. Financial Accountability and Management 15, 419-26.

Pollitt, C. 1990. Managerialism and the public services: the AngloAmerican experience. Cambridge, MA, USA: Blackwell.

Pollitt, C. and Bouckaert, G. 2011. Public management reform: a comparative analysis-new public management, governance, and the Neo-Weberian state. England: Oxford University Press.

Poole, M., Mansfield, R. and Gould-Williams, J. 2006: Public and private sector managers over 20 years: a test of the 'convergence thesis'. Public Administration 84, 1051-76.

Promberger, K. and Rauskala, I. 2003: New Public Management: An Introduction from the UK perspective. Austria, University Innsbruck. http://edoc.vifapol.de/opus/volltexte/ 2010/2273/.

Quinn, R.E. and Spreitzer, G.M. 1997: The road to empowerment: seven questions every leader should consider. Organizational Dynamics 26, 37-49.

Sarker, A.E. 2005: New public management, service provision and non-governmental organizations in Bangladesh. Public Organization Review 5, 249-71.

Seyedin, S.H. and Jamali, H.R. 2011: Health information and communication system for emergency management in a developing country, Iran. Journal of Medical Systems 35, 591-97.

Shaw, R.P. 2004: New trends in public sector management in health: applications in developed and developing countries. Health, Nutrition and Population (HNP) discussion paper. Washington, DC: World Bank. https://openknowledge. worldbank.org/handle/10986/13752.

Simonet, D. 2008: The new public management theory and European health-care reforms. Canadian Public Administration 51, 617-35.

Soeters, R. and Griffiths, F. 2003: Improving government health services through contract management: a case from Cambodia. Health Policy and Planning 18, 74-83.

Tabrizi, J.S., Farahbakhsh, M., Sadeghi-Bazargani, H., Hassanzadeh, R., Zakeri, A. and Abedi, L. 2016: Effectiveness of the health complex model in Iranian primary health care reform: the study protocol. Patient Preference and Adherence 10, 2063. 
Takian, A., Rashidian, A. and Kabir, M.J. 2010: Expediency and coincidence in re-engineering a health system: an interpretive approach to formation of family medicine in Iran. Health Policy and Planning 26, 163-73.

Willis, E., Toffoli, L., Henderson, J., Couzner, L., Hamilton, P., Verrall, C. and Blackman, I. 2016: Rounding, work intensification and new public management. Nursing Inquiry 23, 158-68.

Zanganeh Baygi, M., Seyadin, S.H., Rajabi Fard Mazrae No, F. and Kouhsari Khameneh, A. 2016: Adaptation of goals and organizational structure in Iran's primary healthcare system, a systematic review. Journal of Payavard Salamat 9, 446-58. 